\title{
Article
}

\section{Moving from the letter of the law to the spirit of the law: the challenges of realising the intent of employment equity and affirmative action}

Stella Nkomo

stella.nkomo@up.ac.za

\begin{abstract}
The letter of the law versus the spirit of the law is an idiomatic antithesis which suggests that in interpreting a law there are two choices. One can approach a law literally or one can instead focus on its intent. The relevance of this idiomatic opposition to the Employment Equity Act and its provision for affirmative action is interrogated through the presentation of two case studies demonstrating the obstacles to fully embracing equity and valuing the diversity of South African society.
\end{abstract}

\section{Introduction}

The letter of the law versus the spirit of the law is an idiomatic antithesis which suggests that in interpreting a law there are two choices. One can approach a law literally or one can instead focus on its intent. The relevance of this idiomatic opposition to the Employment Equity Act is best illustrated by describing the broader context within which the legislation was enacted. It is indeed this context that illuminates the spirit or essence of what was intended by its passage. The Employment Equity Act emanates from the Constitution adopted in 1996. Section 9(2) of the Constitution is specifically concerned with the achievement of substantive equality as opposed to formal equality (Dupper and Garbers 2009). Substantive equality takes cognisance of structural inequality in society with a focus on remedy of this inequality (Coetzer 2009: 93). The Constitution also states South Africa's 
vision for the kind of nation it aspires to be: "We, the people of South Africa, recognise the injustices of the past; honour those who have worked for justice and freedom in our land; respect those who have worked to build and develop our country, and believe that South Africa belongs to all who live in it, united in our diversity ...." (Constitution of South Africa 1996: Preamble). This suggests an aspiration of creating an inclusive country that values its diversity.

More than thirteen years ago, the Employment Equity Act of 1998 was promulgated by the South African Parliament. The goal of the Employment Equity Act is to achieve employment equity ${ }^{1}$ by (a) promoting equal opportunity and fair treatment in employment through the elimination of unfair discrimination; and (b) implementing affirmative action to redress the disadvantages in employment experienced by designated groups (Africans, Coloureds, Indians, persons with disabilities and women), in order to ensure their equitable representation in all occupational categories and levels in the workplace (Employment Equity Act, 1998). The intention of the Act is specified in Section 42 which reads, 'The demographic profiles of the national and regional economically active population should be reflected in the employment areas of designated employers. This reflection will show that the workplace is redressed and equality together with a diverse and representative workforce is achieved'(Employment Equity Act 1998). Achieving the latter remains a challenge for a majority of organisations in South Africa. Recent employment data from the Employment Equity Commission suggest slow transformation of the workplace (Department of Labour 2011).

The purpose of this paper is to present the experiences of two organisations that attempted to go beyond a singular focus on numerical targets to also embrace equity and to value diversity in the workplace. These two organisations are part of a larger recent study of employment equity and diversity management practices in twelve South African organisations (Steyn and Kelly 2010; van Aswegen 2008; Booysen, Kelly, Nkomo and Steyn 2007). The study used a case research method that employed a multilevel data collection strategy. Primary data in the form of interviews and focus group discussions as well as observations of workplace interactions were collected. Secondary data took the form of relevant company documents including strategic plans, employment equity plans, and human resource management policies and practices. Organisations in the study ranged from private to public and represented a number of different industries. Overall 
the case studies revealed minimal understanding of the importance and value of equality and diversity in organisations. Instead the dominant approach was a compliance-motivated response to the Employment Equity Act. Transformation efforts, for the most part, focused on 'numerical targets.' The two organisations discussed in this paper reveal the challenges of moving from the letter of the law to embracing the spirit and intent of the law. Despite their best intentions the two organisations did not achieve the aims they had set. The two organisations were a large multinational manufacturer and a university resulting from the merger of two tertiary institutions. These organisations are referred to as Multinational and S University respectively throughout this paper. The paper concludes by raising a number of questions in respect to closing the gap between compliance with, and truly embracing the spirit of, the Employment Equity Act and its antecedents.

\section{Obstacles to Embracing the Spirit of the Law}

Two of the most significant obstacles to embracing equity and diversity were the underestimation of the power of organisation culture and inattention to the larger organisation context within which the organisations operated. Both organisations had declared a strong commitment to employment equity but had also encapsulated a valuing of diversity goal in their strategic plans. According to scholars, a valuing diversity approach is based on recognising the existence of and equal value of people's different identities in terms of race, gender, colour, sex, or sexual preference (Human 2005; Mor Barak 2011). It has gained currency in recent years as a human resource management strategy to address issues of equity and equality in organisations in a number of countries around the world including South Africa (eg April and Shockley 2007; Cox 2001; Klarsfeld, 2010; Heinecken, 2009; Zulu and Parumasur 2009; Nkomo and Stewart 2006; Konrad, Prasad and Pringle 2006). Valuing diversity requires organisations to ensure the goal of a diverse workforce is integrated into its strategic agenda and people management systems (Human 2005). The underlying assumption of the valuing diversity approach is the positioning of diverse employees as a key resource for organisations, not a liability. Proponents of a valuing diversity approach argue organisations that are able to leverage diversity will benefit in terms of creativity, innovation and performance(Cox 2001). Indeed, recent empirical research supports this argument. Herring (2009) in a large scale study of a national sample of private sector organisations in the United 
States found racial diversity was associated with increased sales revenue, more customers, greater market share, and greater relative profits. Similarly, a study of 200 companies in four European Union countries reported companies that implement workforce diversity policies identify important benefits that strengthen long-term competitiveness and, in certain instances, also produce short and medium-term improvement in performance (European Commission, 2003).

In the case of the multinational, its vision for diversity was explicit in stating the value of a diverse workforce as well as the desire to create an inclusive culture where all employees feel appreciated and respected. A diverse workforce was also seen as key to attracting the best talent globally. They also set an employment equity goal of 50-50 representation in their management profile. Multinational instituted a number of interventions to realize its vision. These included establishment of an employment equity committee, diversity workshops, leadership development, targeted recruitment, and cultural awareness days.

On its website, S University stated that a key aspect of achieving the vision to become a leader in higher education is to manage the strength of diversity as a competitive advantage and not merely striving to reflect the demographics of society. In its Employment Equity Plan, a diverse workforce is referred to as 'a source of strength and a powerful key to its success'. Consistent with this vision, $\mathrm{S}$ University put in place a human resource strategy emphasizing staff development opportunities for all and race and gender groups and voluntary diversity training programmes. Its numerical employment equity goal was a 40 percent representation of females and blacks in management and academic positions.

Yet, despite these well intentioned goals, the efforts of both organisations were hampered. The organisation cultures of both organisations were a significant obstacle to making change. Because of the history of apartheid, the organisation cultures in both organisations were white male dominated. Organisation cultures are not neutral phenomenon and are typically shaped and formed by the values and assumptions of the dominant groups in the organisation. As a result, the organization cultures of both organisations might best be described as racialised and gendered. In both cases, top management and the professional ranks were dominated by white males and thus power and decision-making remained in their hands (Benschop and Dorewaard 1998; Acker 2006). The organisation cultures were largely hierarchical and management styles tended to be authority based. 
The dynamics within these cultures negatively impacted blacks and women in obvious but also often subtle ways resulting in experiences of exclusion and marginalisation on many levels. For example, in the case of Multinational, those interviewed described it as a high performance culture driven by a stringent performance management system. The performance driven culture was often used as a pretext for racist assumptions that black people are never competent. Even when well-qualified blacks were hired, it was assumed they would not perform well. Paradoxically, when there was a problem with a person's performance, some managers would not report it because the person was an 'equity' employee Black employees were promoted even though those who had made the promotion decision expected them to fail. In the case of women, white male colleagues generally believed that the shop floor was 'no place' for a woman even though many of the production processes were highly automated. When a woman resigned, it was attributed to her inability to do the job, reinforcing the belief that shop floor jobs are for men. In the rare case where a woman asked for assistance from a colleague, she was rarely given help.

The dominance of Afrikaans language in both organisations acted to exclude blacks who did not speak the language from both formal and informal interactions in the workplace. Women and blacks also found it difficult to become part of the informal gatherings and activities during work and after work. The authority of newly hired blacks in management positions was often undermined by white subordinates who bypassed them to reach a white manager. Both the blacks and women interviewed shared their frustrations with everyday racism and sexism that was part of the organisational cultures in which they found themselves (Essed 1991, Benschop and Dorewaard 1998).

In the case of both organisations, the broader organisational context was not fully considered in the design and implementation of the diversity and equity interventions. In one sense, the influences of the broader context increased the difficulty of realising deep change. The university was in the beginning of its post-merger phase which had several mitigating effects on the valuing diversity intervention. In many respects, the effort and attention required to implement the merger overshadowed attention to the diversity intervention. The merger between a historically black university and a white Afrikaans-medium university created deep racial faultlines exacerbated by significant differences in institutional cultures, degree offerings, administrative systems, unionisation, organisational politics, staff 
qualifications and student bodies. These factors were not explicitly factored into the intervention strategy. Because the structure for the merged institution was not finalised, accountability and responsibility for the intervention was never fully established. Uncertainty and anxiety associated with job security precluded meaningful commitment to equity and diversity. The university actually experienced a decrease in the representation of blacks in academic and senior management positions.

For Multinational, the global context and its desire to be seen as a worldclass company was paramount. In the end, the diversity intervention was driven by the 'business case' (Noon 2007). Diversity was positioned as instrumental to growth and globalisation. The interventions did not have the intended effect envisioned in their diversity goal - we endeavour to create an inclusive culture where all employees feel appreciated for their uniqueness and that contributions are respected. Instead, those interviewed felt little or no change had occurred and a quote from one of those interviewed aptly described the perceptions of employees: 'All different people are welcome as long as you are the perfect Multinational clone: a highly qualified, experienced confident workaholic, who is fiercely patriotic of Multinational and chases the numbers no matter what'. Multinational did reach the numerical targets set although with great difficulty because of the challenges of retaining black staff. Despite recognition that valuing diversity was more than getting the numbers right, it was not successful in truly transforming the organisation as intended.

Another formidable obstacle was management resistance. The extant literature on diversity management in organisations stresses the critical importance of management commitment for the success of any intervention (Cox 2001). Both organisations, however, encountered managerial resistance to the interventions undertaken. Managerial resistance manifested itself in both overt and covert ways. In both organisations, one could argue that top management was committed to equity and diversity as demonstrated by their incorporation of these issues at a strategic level through expression in strategic goals and vision statements. However, the articulation of these efforts did not penetrate through the middle and lower levels of the organisations. The latter two levels are the key implementation agents in any organisation.

Middle managers were the most resistant to the interventions. Acker (2006:460) has argued that dominant group top managers may be more willing to support diversity initiatives and equity objectives than middle managers 
who may lose proportionally more through affirmative action and related interventions. In the case of S University, deans and directors did not act believing that they lacked a 'clear mandate' from top management. Hence they were passive in their implementation of the employment equity strategy. Deans and directors who had a significant presence on the Employment Equity Committee of S University were reluctant to demonstrate leadership or to assume responsibility for its effectiveness because of the perceived lack of a mandate from the top. By not establishing accountability for achieving the equity and diversity vision through clear lines of responsibility, top management in many respects subverted implementation of the valuing diversity strategy. While S University established a transformation office, it was not tasked by management to develop interventions to give effect to the equity and diversity goals. Instead the office was structurally remote and did not have the requisite authority to act without management requests. In both S University and Multinational, employees at lower levels of the organisations were unable to describe the strategic interventions taking place. The latter suggests middle and lower levels of management did not adequately communicate the goals and strategies that had been set at the top.

One of the results of the lack of clear lines of accountability was little direct management attention to the quality of training interventions that took place in the organisations. There was inadequate management oversight of training interventions, resulting in variable quality. At S University, training interventions were targeted to the employee level. Management participation was voluntary and was not part of their key deliverables. This resulted in a disconnect between what employees were learning and the managers who had not been required to engage the issues. Interestingly, in the case of Multinational, management training was mandatory as part of the diversity intervention. However, the focus was on enhancing general leadership skills. It was implicitly assumed that an improvement in leader ability would enhance their ability to value and manage a diverse workforce.

The most salient issue in respect to managerial resistance is that the degree of success depended on management commitment but management in both organisations was white-male dominated. Thus, the very group charged with transformation often had compelling motivations to maintain the status quo (Nkomo and Stewart 2006). Self-preservation and selfinterests often prevented action. This type of resistance was reflected in pushing for change at lower levels with little change in the top management 
profile. At the end of its three year intervention, all divisions of the organisation were still headed by white males. In other instances, managers were unwilling or unable to place equity and diversity as a priority in their day-to-day responsibilities.

The attitudes manifested in the organisations included an additional obstacle. A dominant theme in the interviews with white staff was the denial of the continuing effects of apartheid in the workplace. It is difficult to embrace the spirit of the law if there is no agreement on the problem. The argument for redress and addressing historical inequality through affirmative action faced considerable challenge from assertions of reverse discrimination' from white employees. The interviews with white staff revealed perceptions that recruitment and empowerment of black employees would not only lead to career stagnation in the medium term but in the permanent exclusion of skilled white employees. Expressions of this fear among white staff were centred in the belief that organisations were valuing blacks with formal qualifications over highly experienced whites. Placing and promoting blacks with formal qualifications into jobs which had taken white employees years of experience to obtain was seen as fundamentally unfair. While such fears were often cloaked in a semblance of understanding that 'all people should be given a chance', the sentiment was accompanied with a belief that 'people should earn that chance.' In other words, the notion of meritocracy permeated what was heard in interviews with a number of white employees and managers. Meritocracy subsumes an individual justice model that ensures that the rules of competition are fairly enforced irrespective of race, gender or other differences. It is based on what Sturm and Guinier (1996) label fictive fairness. Fictive fairness refers to sameness of treatment premised on the assumption of a level playing field that if everyone plays by the same rules, the game does not favour or disadvantage anyone. The attitudes in the two organisations are similar to what has been reported previously in other organisational research (Vermeulen and Coetzee 2006).

Of greater concern, however, are the implications of their resistance. The views expressed suggest that there was little recognition and cognizance of the effects apartheid on the access to opportunities for blacks as a justification for affirmative action. Scholars have recently referred to this phenomenon as 'equity fatigue' - people being impatience with a continued focus on equity (Ahmed 2007) or perhaps more apt in this case is 'apartheid fatigue'tired of being reminded of the social injustices of apartheid. There was little acceptance of the need for a group justice model or viewing equality as social 
justice-redressing the consequences of past racial discrimination (Tomei 2003; van Jaarsveld 2000). It would appear that dominant group employees in the organisations were unable or unwilling to recognise the continued effects of racial segregation in organisations. Instead such injustices were relegated to something that had happened in the past. We also found similar attitudes among some of the management staff who preferred to recruit and hire based on merit and not because "they are previously disadvantaged."

\section{Conclusion}

The provisions of the Employment Equity Act as well as its antecedents, the Constitution and even the Freedom Charter, clearly indicate an intent to use the law to redress the historical inequality in the workplace. The emphasis is upon equality as social justice where the goal is to reduce and eventually eliminate inequalities between dominant and previously disadvantaged groups (Tomei 2003: 411). Social justice equality and equity seeks to ensure fair participation of the previously disadvantaged groups in the workplace. Affirmative Action has been the main mechanism to achieve such equality (Denton and Vloeberghs 2003). But in addition these historical declarations also suggest aspirations beyond redress. They envision a society based on the principle of valuing the diversity of the South African population. Ultimately, this aspiration should also be achieved in the workplace. Both organisations described in this paper attempted to position equity within a broader valuing diversity principle. Yet, the interventions were not fully effective. One organisation reached its numerical goal with little real change as perceived by employees. In both organisations, the effort to value diversity was not able to penetrate powerful obstacles embedded in lingering legacies of racial segregation and hegemonic white-male organisational cultures. Clearly, increasing the body count does not reduce inequality given how inequalities are deeply embedded in organisation structures that remain hostile to difference (Spivak 2000). The experiences of these two organisations raise a number of questions in respect to advancing equity and valuing diversity in South Africa.

First, they raise the question of whether a valuing diversity or unity in diversity emphasis can overcome systemic inequalities in the workplace as intended by the Employment Equity Act and its antecedents. This is a rather important question especially since diversity management is being increasingly proffered as the solution to managing and leveraging a diverse workforce (Society for Human Resource Management 2009). Organisations 
that aspire to be viewed as world class typically adopt what are accepted as global best practices. The diversity approach to equality is based on the idea that by demonstrating and making the 'business case' for diversity, organisations will have a strong motivation to change because it goes to the heart of the business of the organisation (Cox, 2001). It has also opened the way to including a broader variety of identities beyond race, gender and ethnicity that could potentially contribute to the performance of organisations, such as age, sexual orientation, disability and even individual traits (Zanoni, Janssens, Benschop and Nkomo, 2010). But as the two cases demonstrate, the business case is not enough because inequality and the devaluing of diversity can still occur. As illustrated by Multinational's experience, instrumental positioning of diversity (i.e. as competitive advantage) may result in diluting the value of diversity because inclusion often requires assimilation to organisational priorities. Indeed, black, coloured, and Indian employees were valued as long as they fitted into the existing organisational culture. A very instrumental orientation may also lead to a neglect of social justice whose main goal is to redress inequalities between dominant and oppressed groups. It is important to note that both affirmative action and valuing diversity are concepts that originated in the United States. Scholars have argued that the affirmative action approach in the United States cannot fully serve as a model for South Africa primarily because the beneficiaries of affirmative action are a numerical majority unlike its targets in the United States (Dupper 2004). But more importantly, except for those companies who do direct business with government, affirmative action in the United States is voluntary (Kelly and Dobbin 1998). However such an option is not feasible for South Africa. Unless interventions directly tackle power and privilege institutionalised in organisational structures and processes, historical inequalities are simply re-created and re-enforced (Linnehan and Konrad 1999).

A second question is what kinds of interventions are needed to help dominant group organisational members accept the legitimacy of redress? What is clear from the two cases is that a prerequisite to getting resistant white employees to value diversity is helping them to accept the legitimacy of redress and affirmative action. Training and educational programmes must not avoid the difficult issues of prejudice, discrimination and historical disadvantage created by apartheid. Cultural awareness training alone that focuses on exposure to cultural differences often distracts from the harsh realities of our apartheid past. Recent social psychological research on 
prejudice and discrimination reduction indicates that diversity training that helps participants to understand the systemic nature of inequality are more effective than interventions that avoid the issue (Adams, Edkins, Lacka, Pickett and Cheryan (2008).

Critiques of the valuing diversity approach have pointed out that while the word 'diversity', invokes difference it does not necessarily evoke commitment to action or redistributive justice (Deem and Ozga 1997:33). The cases illustrate that having diversity as a key value is not always a guarantee of actually doing diversity - saying does not always lead to doing (Ahmed 2007: 249). To this end, one mandate is clear. Managers in organisations must be held accountable and responsible for eliminating inequalities. Research on the impact of diversity interventions in organisations has found evidence that setting managerial responsibility and accountability within well-defined structures for change had a stronger effect than diversity training (Kalev, Kelly and Dobbin 2006). In other words, organisational leaders have to be held accountable for implementing systemic changes to organisational and human resource management practices. In fact, empirical studies of the relationship between valuing diversity and organisation performance have reported that organisations that were racially diverse and who also followed a proactive diversity-management strategy had the greatest benefit to performance (Cunningham 2009).

South African organisations will have to tackle both redress and how to create organisations cultures that are able to value and embrace the diversity of the country. Redress and valuing diversity cannot simply be viewed as mutually exclusive given South Africa's vision of unity in diversity (Habib and Bentley 2008). In the short term, the focus must be on redressing inequities. However, organisations in South Africa must strive in the long-term to define an approach for valuing diversity that goes beyond an instrumentalist view to one that is transformative in creating workplaces and organisational cultures that equally value the aspirations and talents of all social groups (Erasmus 2009). Part of this transformation means ensuring that the talents of those who have been historically excluded are equally valued and esteemed. Navigating the slippery slope of redress, equity and equality in the workplace is not an easy challenge but one that must be met if we are going to move from the letter of the law to the spirit of the law and realise the aspirations of a nation united through its diversity as envisioned in the Constitution. 


\section{Notes}

1. The concept of equity is general defined as the process of being fair. To ensure fairness, measures must often be available to compensate for historical and social disadvantages that prevent certain groups from otherwise operating on a level playing field. Equity and equality are inextricably linked. Equality refers to the allocation of resources, opportunities, support and encouragement without any discrimination on the basis of a demographic characteristic (for example, race, gender, etc).

\section{References}

Acker, J (2006) 'Inequality regimes: Gender, class and race in organisations', Gender \& Society 20(4).

Adams, G, V Edkins, D Lacka, K Pickett and S Cheryan (2008) 'Teaching about racism: pernicious implications of the standard portrayal', Basic and Applied Social Psychology 30.

Ahmed, S (2007) 'The language of diversity', Ethnic and Racial studies 30(7).

April, K and M Shockley (2007) Diversity in Africa: the coming of age of a continent. Basingstoke: Palgrave Macmillan.

Benschop, Y and H Dorewaard (1998) 'Covered by equality: the gender subtext of organizations', Organization Studies 19(5).

Booysen, L, C Kelly, SM Nkomo and M Steyn (2007) 'Rethinking the diversity paradigm: South African practices', International Journal of Diversity in Organisations, Communities \& Nations 7.

Coetzer, N (2009) 'Affirmative action: the sword versus shield debate continues', 21 SA Merc LJ.

Constitution of South Africa (1996).

Cox, T (2001) Creating the Multicultural Organization: A strategy for capturing the power of diversity. SanFrancisco: Jossey-Bass.

Cunningham, GB (2009) 'The moderating effect of diversity strategy on the relationship between racial diversity and organizational performance', Journal of Applied Psychology 39(6).

Denton, M and D Vloeberghs (2003) 'Leadership challenges for organisations in the New South Africa', Leadership \& Organizational Development Journal 24.

Department of Labour (2011) $11^{\text {th }}$ CEE Annual Report 2010-2011. Johannesburg, South Africa.

Dupper, O (2004) 'In defence of affirmative action', South African Law Journal (121).

Dupper, O and C Garbers (eds) (2009) Equality in the Workplace: Reflections from South Africa and Beyond. Cape Town: Juta. 
Employment Equity Act (1998) Pretoria: South African Government.

Erasmus, P (2009) 'The unbearable burden of diversity', Acta Academia 41(4).

European Commission (2003) Costs and Benefits of Diversity. Kent, UK: European Commission, Directorate-General for Employment, Industrial Relations and Social Affairs.

Essed, P (1991) Understanding Everyday Racism: an interdisciplinary theory. Newbury Park, CA: Sage.

Habib, A and K Bentley (2008) Racial Redress and Citizenship in South Africa. Pretoria: HRSC Press.

Heinecken, L (2009) 'A diverse society, a representative military? The complexity of managing diversity in the South African Armed Forces', Scientica Militaria: South African Journal of Military Studies 37(1).

Herring, C (2009) 'Does diversity pay? Race, gender and the business case for diversity', American Sociological Review 74.

Human, L (2005) Diversity Management for Business Success. Pretoria: Van Schaik.

Kalev, A, F Dobbin, and E Kelly (2006) 'Best practices or best guesses? Assessing the efficacy of corporate affirmative action and diversity policies', American Sociological Review 71(4).

Kelly, E and F Dobbin (1998) 'How affirmative action became diversity management', American Behavioral Scientist 41(7).

Klarsfeld, A (ed) (2010) International Handbook on Diversity Management at Work: country perspectives on diversity and equal treatment. Cheltenham: Edward Elgar.

Konrad, AM, P Prasad, and JK Pringle (eds) (2006) Handbook of Workplace Diversity. London: Sage.

Linnehan, F and AM Konrad (1999) 'Diluting diversity: implications for intergroup inequality in organizations', Journal of Management Inquiry 8(4).

Mor Barack, ME (2011) Managing diversity: toward a globally inclusive workplace. Thousand Oaks, CA: Sage.

Nkomo, SM and MM Stewart (2006) 'Diverse identities in organisations', in SR Clegg, C Hardy and WR Nord (eds) Handbook of Organization Studies, 2nd edition. London: Sage.

Noon, M (2007) 'The fatal flaws of diversity and the business case for ethnic minorities', Work, Employment and Society 21.

Steyn, M and C Kelly (2010) Widening circles: Case studies of transformation: Consolidated report of DEISA case studies. Cape Town: iNCUDISA.

Society for Human Resource Management (2009) Global diversity and inclusion: perceptions, practices and attitudes. Alexandria, VA: SHRM. 
Spivak, GC (2000) 'Claiming transformation: travel notes with pictures', in S Ahmed, S Kilby, JC Lury, M McNeil, and B Skeggs. Transformations: thinking through feminism. London: Routledge.

Strum, S and L Guinier (1996) 'The future of affirmative action: reclaiming a novel idea', California Law Review (July).

Tomei, M (2003) 'Discrimination and equality at work: A review of the concepts', International Labor Review 142(4).

van Aswegen, L (2008) Diversity Explored. Netherlands: Rozenburg.

van Jaarsveld, IL (2000) 'Affirmative action: a comparison between South Africa and the United States', Managerial Law 42(6).

Vermeulen, L and M Coetzee, M (2006) 'Perceptions of the dimensions of the fairness of affirmative action: A pilot study', South African Journal of Business Management 37(2).

Zanoni, P, M Janssens, Y Benschop, and SM Nkomo (2010) 'Unpacking diversity, grasping inequality: Rethinking difference through critical perspectives', Organization: the critical journal of organization, theory and society 17(1).

Zulu, P and S Parumasur (2009) 'Employee perceptions of the management of cultural diversity and workplace transformation', South African Journal of Industrial Psychology 35(1). 